\title{
THE SYNDROME OF ABDOMINAL AORTIC ANEURYSM RUPTURING INTO THE GASTROINTESTINAL TRACT
}

\author{
Summary of the Literature and Case Report \\ Homer H. Hunt, M.D., and Carl V. Weller, M.D. \\ ANN ARBOR, Mich.
}

$\mathbf{R}_{\text {UPTURE of an aneurysm of the abdominal portion of the aorta into the }}$ will usually suggest the diagnosis. This dramatic accident is sufficiently rare to justify the continued reporting and collection of casés for analysis. In this paper, another cxample of the rupture of such an aneurysm into the duodenum is rccorded, and the list of reported cases is brought up to date.

Including the one reported here, forty-one cases have now been collected. Undoubtedly others are concealed in the numerous studies of aortic aneurysm in general. In 1943, Rottino, ${ }^{1}$ in a very thorough search, found thirty-one examples of rupture of an abdominal aortic aneurysm and added a case of his own. The essential clinical and morphologic data concerning the group, so far as they were obtainable, were arranged by him in tabular form. Our Table I, adding nine cases, is purposely constructed as a continuation of that presented by Rottino, using the same headings and continuing his serial numbering. Since the cases reported by Nunneley ${ }^{2}$ and Peñas ${ }^{3}$ were not known to Rottino, his own case becomes the thirty-fourth in the series. References to the cases in Rottino's table will not be repeated except that for Vehling, ${ }^{4}$ whose dissertation, available in microfilm, can now be cited more accurately.

Probable examples, which do not qualify for inclusion in Table I because perforation was impending rather than actual, or because it is not clear that the aneurysm was primarily aortic, can be found among studies reported from other points of view. Washburn and Wilbur ${ }^{5}$ described obstruction of the third portion of the duodenum by an aneurysm of the abdominal aorta. The patient was a woman, aged 67 , with a large, pulsating, epigastric mass. There had been no blood in the vomitus, but later there was a slight trace of blood in a test meal and occult blood in the stools. Rupture must have been impending in this case. The clinical diagnosis was confirmed when a posterior gastroenterostomy was performed for the relief of obstruction.

In an analysis of the symptoms and signs in a group of twenty-four cases of abdominal aneurysm, Eliason and $\mathrm{McNamee}^{\mathrm{Il}}$ found massive hematemesis and melena each mentioned once. Although pain was the predominant symptom in

From the Department of Pathology, University of Michigan.

Received for publication April 18, 1946. 
AMERICAN HEART JOURNAL

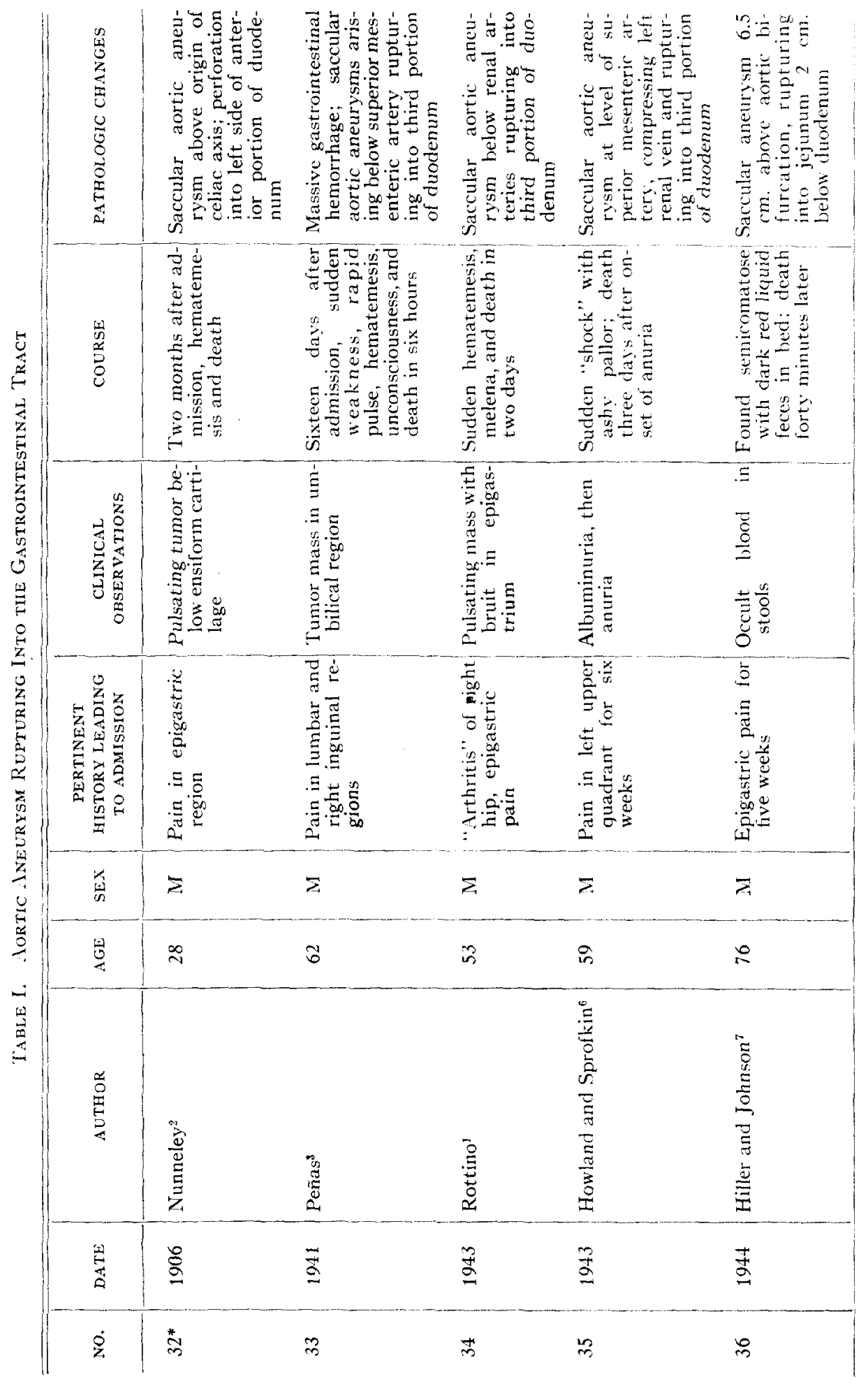


HUNT AND WELLER: RUPTURE OF ABDOMINAL AORTIC ANEURYSM

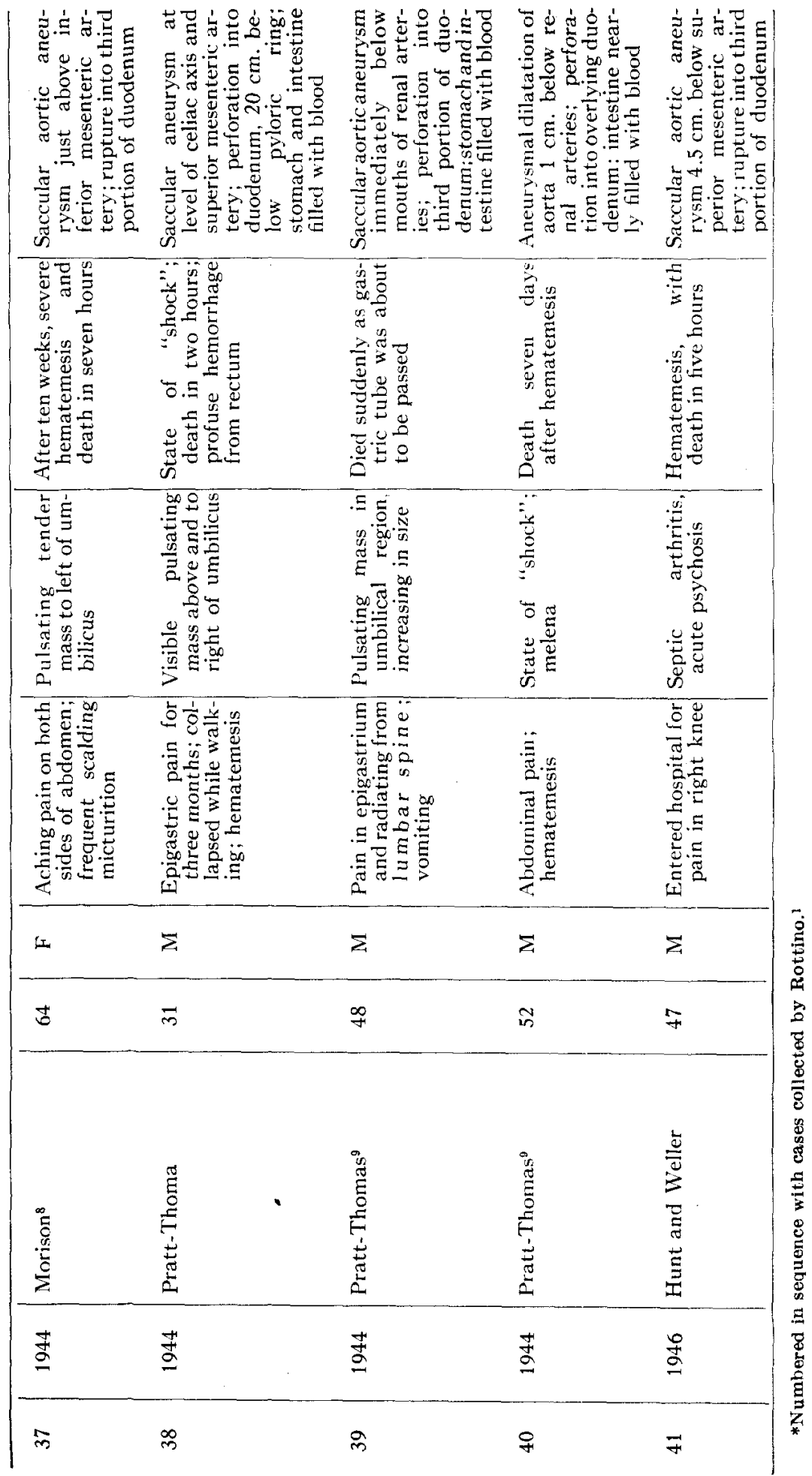


the group as a whole, reference is made to one patient who had very little pain but did have massive hematemesis from rupture of an aneurysm of the celiac axis into the jejunum. Death occurred twenty-four hours after the onset of hemorrhage. This case and one other, attributed to the celiac axis, are excluded from Table I.

Scott ${ }^{11}$ included lesions of any abdominal artery in his report of ninety-six cases of abdominal aneurysm. "Massive gastrointestinal hemorrhage followed rupture into the duodenum in one patient." In his table a second patient is recorded as having hemorrhage into the duodenum following rupture. Whether one or both of these were aortic aneurysms is not stated.

A brief account of our case follows.

\section{CASE REPORT}

I. B., No. 483037, was an unmarried Swedish bricklayer, aged 47. He was admitted to the University of Michigan Hospital with a painful left knee as his chief complaint. Physical evidences of septic arthritis were present and bone destruction was found roentgenographically. The patient developed an acute psychosis and a reliable history could not be obtained. However, he referred the onset of pain to a period about one month prior to admission. Venereal infection was denied, but exposure six weeks before entry was admitted. Serologic test of the blood (Kahn) was negative on two occasions. The gonococcal complement fixation test of the blood serum was strongly positive. The patient was given sulfathiazole, and three operative procedures for drainage of the left knee were carried out. On the third postoperative day, at 5 A.M., the patient had a sudden hemorrhage from the mouth, amounting to about 300 c.c. of fluid and clotted blood. A medical consultant suggested pulmonary infarction, but roentgenograms of the chest were negative. None was made of the abdomen. At 10:15 A.M. of the same day, the patient had a second hemorrhage and expired.

Autopsy.-At autopsy (A-420-AS), the stomach, duodenum, and entire small bowel were found to be filled with a jellylike blood clot forming a cast of the lumen. In the transverse segment of the third portion of the duodenum there was a small, irregular opening which communicated with a firm, somewhat elastic, retroperitoneal mass. After removing the duodenum and aorta together, this mass was found to be a saccular aneurysm protruding from the right anterolateral surface of the abdominal aorta. The sac measured $6 \mathrm{~cm}$. vertically, $4.5 \mathrm{~cm}$. transversely, and $3.5 \mathrm{~cm}$. ventrodorsally. Its upper border was $4.5 \mathrm{~cm}$. below the orifice of the superior mesenteric artery and its lower border $2 \mathrm{~cm}$. above the iliac bifurcation. The mouth of the sac lay to the right of the inferior mesenteric artery and measured 2.5 by 2 centimeters. The wall of the sac was composed of thick fibrous and calcareous laminae (Figs. 1 and 2). The remainder of the abdominal aorta showed thickening of the wall, loss of elasticity, widening of the lumen, and numerous yellowish-gray, elevated, hyaline plaques against a grayish-white intima. There were also areas of atheromatous "ulceration," but the gross features of syphilitic aortitis were not found.

Sections of all organs were examined microscopically. The heart showed atherosclerotic changes of the coronary arteries and at the bases of the aortic cusps. In the myocardium there were scattered interstitial infiltrations of mononuclear cells, in part eosinophiles, which were thought to be due to the use of sulfathiazole.

The aorta was examined in sections from several levels. In the upper portion of the thoracic aorta, atheromatous changes were of but slight degree. There was a very moderate increase in the blood vessels of the adventitia, about some of which there was a slight lynphocytic infiltration. In the abdominal aorta there were very marked atheromatous lesions of the intima, with deposition of cholesterol and calcareous plaques. The media showed areas of necrosis with fragmentation and ultimate loss of elastic fibers. In the adventitia there were infiltrations of 


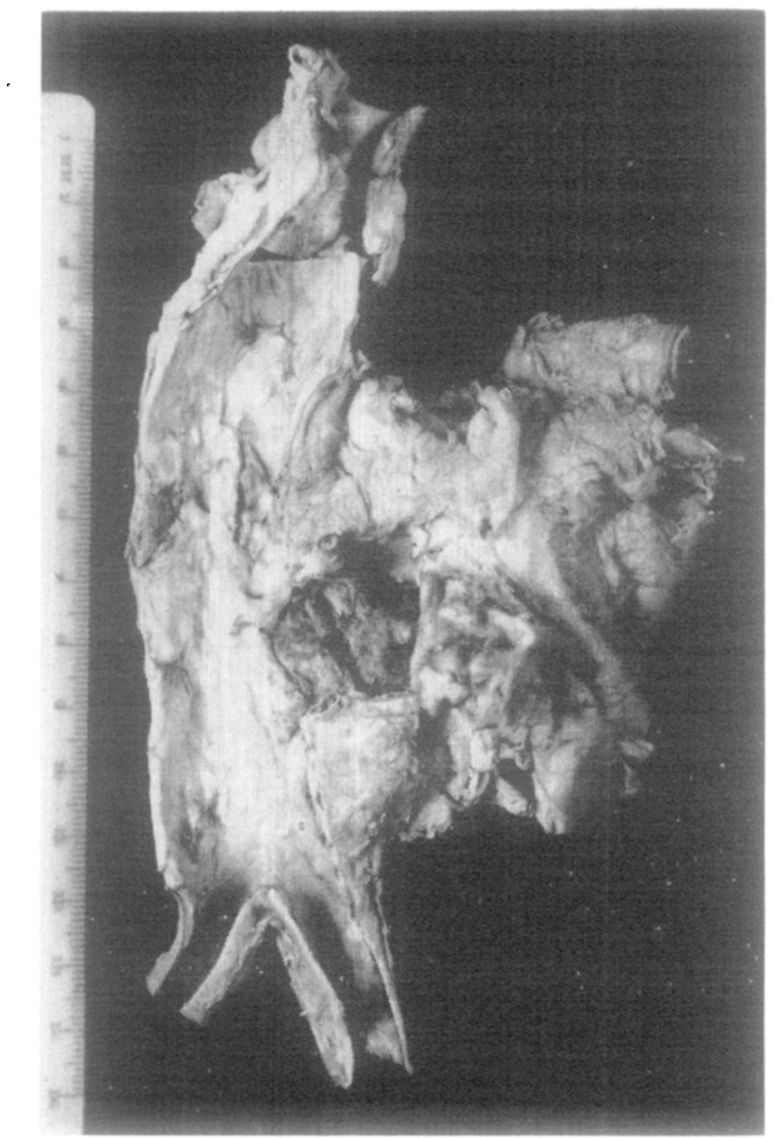

Fig. 1.-The abdominal aorta has been opened approximately along the mid-dorsal line. The mouth of the aneurysmal sac is shown to the right of the opening of the inferior mesenteric artery. The adherent duodenum is largely concealed by the sac of the aneurysm.

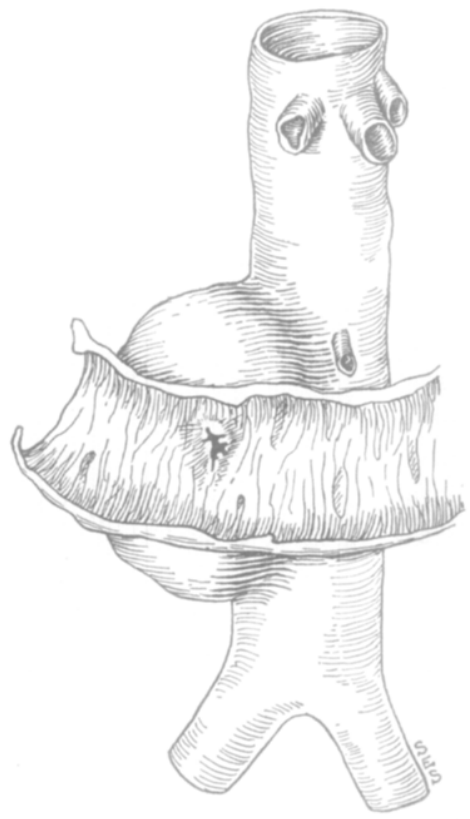

Fig. 2.-This schematic drawing, prepared from a photograph and sketch made at the time of the autopsy, shows more clearly the anatomic relations of the aneurysm. Rupture into the duodenum occurred at the summit of the convexity of the anterior wall of the sac. 
lymphocytes and plasma cclls, but the changes found were not such as to justify a diagnosis of syphilitic aortitis.

Near the point of perforation of the aneurysm into the duodenum the were organizing, fibrinous peritonitis and necrosis and leucocytic infiltration of the mucosa.

A section of synovial membrane from the left knee showed active chronic pyogenic inflam. mation with numerous plasma cells. This was considered to be fully compatible with the clinical impression of gonococcal arthritis.

The pathologic diagnoses were: large saccular aneurysm of the abdominal aorta, with rupture into the third portion of the duodenum and massive hemorrhage into the bowel; hematemesis, with aspiration of blood into the lungs; advanced aortic atherosclerosis; organizing fibrinous peritonitis of the duodenum; coronary atherosclerosis; old epicarditis; subepicardial fatty atrophy of the myocardium; left ventricular myocardial hypertrophy; interstitial myocardial infiltations of large mononuclear cells and eosinophiles (sulfathiazole?); pulmonary congestion and edema; beginning terminal lobular pneumonia; degenerative fatty infiltration of the liver and kidneys; septic arthritis of the right knee (gonococcal?); cholelithiasis.

\section{DISCUSSION}

Incidence as to Sex and Age.-This augmented series adds to the earlier emphasis upon the greater liability of men to this syndrome. With thirty-five of forty-one examples in men, a 6:1 ratio is found. The range in age remains unaltered, from 20 to 81 years. While the distribution by decades is fairly uniform between these extremes, correction for total number living would show an increasing incidence beginning with the sixth decade. It can be due only to chance that for four of the thirty-eight patients the age was 28 years. Yet the occurrence of eight cases in the six-year period between 27 and 32 years-of-age emphasizes the importance of this syndrome in a comparatively young group.

Location of the Aortic Aneury'sm.--In sixteen cases the level at which the aortic aneurysm had developed was not stated with sufficient exactness to be used in tabulation. Moreover, the large size of many of these aneurysms in comparison to the small distances between successive aortic branches must have rendered exact localization impossible in many cases. Locations were specified as follows: above celiac axis, two cases; at celiac axis, three; above superior mesenteric artery, one; at superior mesenteric artery, one; below superior mesenteric artery, five; above renal vessels, one; below renal vessels, six; below inferior' mesenteric artery, two; lower abdominal aorta, one; above aortic bifurcation, three.

Location of Rupture Into Gastrointestinal Tract. - $\Lambda$ s found by Rottino, the third portion of the duodenum is the portion of the gastrointestinal tract into which perforation of an abdominal aortic aneurysm occurs most frequently. This site was specified, or could be deduced, in twenty-nine of the forty-one cases. In two others, perforation was into the second portion of the duodenum, and in two into the duodenum, without specification as to the portion. Of the remaining cases, five showed perforation into the stomach, two into the jejunum, and one into the small bowel, with the region unspecified. The reasons for the preponderance of perforation into the third portion of the duodenum are anatomic, 
depending in part upon the extensive area in which this portion of the duodenum is in relationship to the anterior aortic wall and also upon its firm fixation to the aorta, since the duodenum is retroperitoneal in this portion.

\section{CLINICAL MANIFESTATIONS}

The syndrome produced by the rupture of an abdominal aortic aneurysm into the gastrointestinal tract combines the features of abdominal aneurysms in general with those of hemorrhage into the alimentary tract. An accurate antemortem diagnosis may be possible in spite of the rarity of the condition.

For the basic clinical picture of abdominal aortic aneurysm, Kampmeier ${ }^{12}$ gave the following as important diagnostic points: presence of an abdominal tumor ( 60 per cent of all cases); expansile pulsation of the tumor (in 98 per cent of those with tumors); roentgenologic evidence of a calcified abdominal mass, of vertebral erosion, or of an indefinite soft tissue mass (confirming evidence being found by this method in 75 per cent of thirty-two cases in which it was used). With any abdominal aortic aneurysm, death is usually due to hemorrhage, whether the aneurysin is saccular or dissecting. Sometimes death is almost instantaneous, but it may be delayed for hours or days. Lipshutz and Chodoff ${ }^{13}$ added to the general picture of abdominal aneurysm the following, as evidence that rupture had occurred: vascular crisis and a state of shock, a high leucocyte count, moderate elevation of diastase content of the urine.

All of the diagnostic criteria summarized by Kampmeier and by Lipshutz and Chodoff apply to the cases of aneurysms in which perforation in to the gastrointestinal tract is impending or has occurred. The tumor mass is usually epigastric in position and it is frequently expansile and pulsating. Pain is the chief complaint and may be abdominal or in the lumbar region. Hematemesis and melena are usual terminal features but, as with thoracic aortic aneurysms, there may be a premonitory seepage of blood for days or weeks before the final exsanguinating hemorrhage. This may be discovered through blood-tinged vomitus or as occult blood in the stools. Death may occur immediately, or after a variable interval, following the copious hematemesis or escape of fresh blood from the rectum which completes the diagnostic picture. The report by Manson ${ }^{14}$ is typical. "I was called to a passenger train on June 18, 1936, to attend a man who was seriously ill. This man was found to be lying on his back in a firstclass lavatory with his trousers down, in a mass of blood and feces. He was blanched and unconscious, and at first sight scemed to be dead." A pulsating tumor was felt in the epigastrium. This patient died five days later and was found to have a saccular aneurysm of the abdominal aorta, which had ruptured into the duodenum. In our own case, hematemesis marked the occurrence of rupture.

There are additional features which may lead the clinician away from the correct diagnosis unless their logical association with this syndrome is recognized. For instance, a high leucocyte count appears to be a constant feature during the period between actual rupture and death. Again, a detailed history of "indi- 
gestion" may seem to point so clearly to peptic ulcer that the physical and roentgenographic evidences of aneurysm may be overlooked. The frequency with which an elevated value for urinary diastase will be found has not yet been established but deserves further study. Impairment of renal function has been observed in many instances and depends chiefly upon interference with one or both renal arteries. In the case described by Howland and Sprofkin, ${ }^{6}$ in which there was terminal anuria, the mouths of the renal arteries were included in the aneurysmal sac and a thrombus extended into the right renal artery.

\section{SUMMARY}

With the new case, which is reported in this paper, forty-one examples of rupture of an aneurysm of the abdominal aorta in to some portion of the gastrointestinal tract are known to be available in the literature. In 71 per cent, rupture was into the third portion of the duodenum. The condition has been six times more frequent in men than in women. While the ages were widely distributed, the occurrence of eight cases between 27 and 32 years-of-age indicates the importance of this condition in relatively young patients. The resulting syndrome combines the features of abdominal aneurysm with those of profuse hemorrhage into the gastrointestinal tract. Hematemesis, often with abundant hemorrhage from the rectum, usually marks the onset of the terminal phase.

\section{REFERENCES}

1. Rottino, A.: Aneurysm of Abdominal Aorta, With Rupture Into the Duodenum. Case Report and Review of the Literature, AM. HEART J. 25: 826, 1943.

2. Nunneley, F. P.: Aneurysm of the Abdominal Aorta, London, 1906, Baillière, Tindall \& Cox, 121 pp.

3. Peñas, M. D.: A Rare Cause of Fatal Haematemesis (Rupture of Aneurysm of Abdominal Aorta Into Duodenum), U. S. T. J. Med. 1: 303, 1941.

4. Vehling, Carl: Perforation der Aorta in den Digestionstractus, Inaugural Dissertation, Erlangen, 1878, $40 \mathrm{pp}$.

5. Washburn, R. N., and Wilbur, D. L.: Obstruction of the Duodenum Produced by Aneurysm of the Abdominal Aorta, Proc. Staff Meet., Mayo Clin. 11: 673, 1936.

6. Howland, E. S., and Sprofkin, B. E.: Saccular Aneurysm of the Abdominal Aorta. Report of a Case With Terminal Anuria and Rupture Into the Duodenum, Am. J. M. Sc. 206: 363, 1943.

7. Hiller, G. I., and Johnson, R. M.: Nbdominal Aortic Ancurysm. Rupture Into the Je. junum Preceded by Occult Blood in the Stool, Am. J. M. Sc. 207: 600, 1944.

8. Morison, J. E.: Rupture of Aortic Aneurysm Into the Duodenum, Brit. M. J. 2: 244, 1944.

9. Pratt-Thomas, H. R.: Aneurysm of the Abdominal Aorta With Rupture Into the Duodenum. Report of Three Cases, Am. J. Clin. Path. 14: 405, 1944.

10. Eliason, E. L., and McNamee, H. G.: Abdominal Aneurysm. A Report of Twenty-Four Cases. Am. J. Surg. 56: 590, 1942.

11. Scott, V.: Abdominal Aneurysms. A Report of Ninety-six Cases, Am. J. Syph., Gonor. \& Ven. Dis. 28: 682, 1944.

12. Kampmeier, R. H.: Aneurysm of the Abdominal Aorta. A Study of 73 Cases, Am. J. M. Sc. 192: 97, 1936.

13. Lipshutz, B., and Chodoff, R, J.: Diagnosis of Ruptured Abdominal Aortic Aneurysm. Report of a Case, Arch. Surg. 39: 171, 1939.

14. Manson, J. S.: Rupture of Aorta Into Duodenum, Brit. M. J. 1: 121, 1937. 